\title{
Biosimilars: A ReVieW OF Regulatory PERSPECTIVE IN INDIAN CONTEXT
}

\author{
Ishita Sharma, Raj Kumar Vaya*, Ayush Garg \\ Department of Pharmaceutics, Pacific College of Pharmacy, Pacific University, Udaipur 313003, Rajasthan
}

*E-mail: vayaraj7@gmail.com

Tel.: +919950678728.

Received: Feb 23, 2017 / Revised: Mar 29, 2017 / Accepted: Mar 30, 2017

It seems biological medicines are set to play a major part in the pharmaceutical industry's future and they already play a major part in its current growth. At the moment, biologicals account for 10 $15 \%$ of the pharmaceutical market. More than one-fifth of new medicines launched on the world market each year are now biotechnology derived. The objective of this article is to facilitate regulatory requirements for the approval process of Biosimilars and the need for Biosimilar product class-specific guidelines in Regulated and emerging markets. Biosimilars are biological products that are the replicas of their innovator biopharmaceuticals. Specified regulations, and approval process of generic version of biologicals exists depending on the country. Each class of biologic varies in its benefit / risk profile, the nature and frequency of adverse events, the breadth of clinical indications, and whether surrogate markers for efficacy are available and validated. But most of the countries do not have specific guidelines for potential market biological products like monoclonal antibodies (mAbs), interferon beta, and insulin.

Key words: Biosimilars, Generics, Recombinant technology, WHO, FDA.

\section{INTRODUCTION}

A biosimilar (also known as follow-on-biologic or subsequent entry biologic) is a biologic medical product which is almost an identical copy of an original product that is manufactured by a different company. Biosimilars are officially approved versions of original "innovator" products, and can be manufactured when the original product's patent expires (Figure 1).

Reference to the innovator product is an integral component of the approval. Unlike with generic drugs of the more common small-molecule type, biologics generally exhibit high molecular complexity, and may be quite sensitive to changes in manufacturing processes. Drug related authorities such as European Medicines Agency (EMA), Food and Drug Administration (FDA), and Health Canada hold their own guidance on requirements for demonstration of the similar nature of two biological products in terms of safety and efficacy (Naik et al 2104).

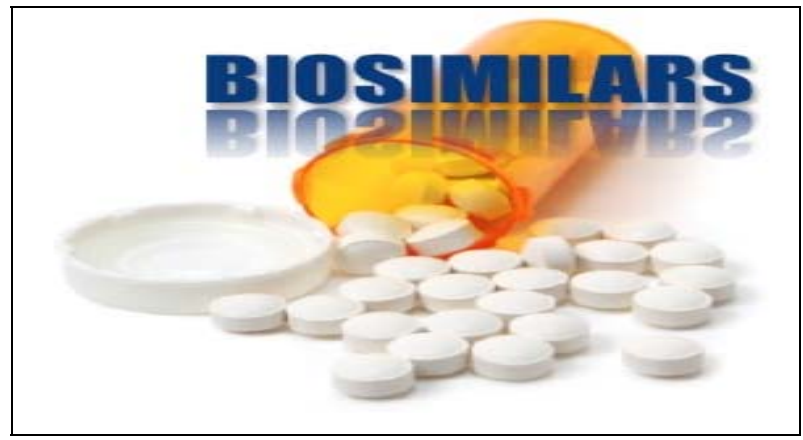

Fig. 1. Biological medical product - biosimilar

Biosimilars vs Generics

Biosimilars differ from generics - in complexity, in the manufacturing processes and in the data needed to demonstrate similarity for approval. Table 1 enlists some major differences among these two classes: 
Table 1. Major differences between biosimilars and generics

\begin{tabular}{|c|c|c|}
\hline Properties & Generics & Biosimilars \\
\hline Size & Small & Large \\
\hline Molecular weight & $<500-900$ Daltons & 4000 to $>140,000$ Daltons \\
\hline Structure & Simple and well-defined & $\begin{array}{c}\text { Complex with potential } \\
\text { structural variations }\end{array}$ \\
\hline Manufacturing & $\begin{array}{c}\text { Predictable chemical process to } \\
\text { make identical copy }\end{array}$ & $\begin{array}{c}\text { Specialized biological process } \\
\text { to make similar copy }\end{array}$ \\
\hline Complexity & Easy to fully characterize & $\begin{array}{l}\text { Difficult to characterize due to } \\
\text { heterogenity }\end{array}$ \\
\hline Stability & Relatively stable & $\begin{array}{l}\text { Sensitive to storage and } \\
\text { handling conditions }\end{array}$ \\
\hline Adverse immune reaction & Lower potential & Higher potential \\
\hline Manufacturing quality tests & $\leq 50$ & $\geq 250$ \\
\hline Approval requirements & $\begin{array}{l}\text { Small clinical trials in healthy } \\
\text { volunteers }\end{array}$ & $\begin{array}{l}\text { Large clinical trials } \\
\text { in patients }\end{array}$ \\
\hline
\end{tabular}

\section{Advantages}

- The operating profit margin of traditional generic drugs is roughly $20 \%$, but depending on the biosimilar product, profit margins have the potential to be somewhat higher, as much as $30 \%$

- Treatment cost with biosimilars is lesser than innovators biological drug

- Biopharmaceuticals represent one of the fastest growing segments of pharmaceuticals industry

- Patent of original product is going to expire and therefore opportunity for generic versions of biopharmaceutical is very large (Naik et al 2104)

\section{Disadvantages}

- Biosimilars are less stable than chemical based pharmaceuticals and thus require cold chain distribution and have a shorter shelf life. This increases the cost and complexity of distribution.

- The cost of development will be significantly higher than for chemical-based generics (Naik et al 2104)

\section{Government rules and regulations for biosimilar drugs in India}

The "Guidelines on Similar Biologics" prepared by Central Drugs Standard Control Organization (CDSCO) and the Department of Biotechnology (DBT) lay down the regulatory pathway for Similar Biologic claiming to be Similar to an already authorized Reference Biologic. A Similar Biologic product is that which is similar in terms of quality, safety and efficacy to an approved Reference Biological product based on comparability.
CDSCO is the national regulatory authority in India that evaluates safety efficacy and quality of drugs in the country. DBT through Review Committee on Genetic Manipulation (RCGM) is responsible for overseeing the development and preclinical valuation of recombinant DNA derived products.

\section{Applicable regulations and guidelines}

The Similar Biologics are regulated as per the Drugs and Cosmetics Act, 1940, the Drugs and Cosmetics Rules, 1945 (as amended from me to me) and Rules for the manufacture, use, import, export and storage of hazardous microorganisms / genetically engineered organisms or cells, 1989 (Rules, 1989) notified under the Environment (Protection) Act,1986.

Various applicable guidelines are as follows:

- Recombinant DNA Safety Guidelines, 1990

- Guidelines for generating preclinical and clinical data for rDNA vaccines, diagnostics and other Biological, 1999

- CDSCO guidance for industry, 2008

- Submission of Clinical Trial Application for Evaluating Safety and Efficacy

- Requirement for permission of New Drug Approval

- Post approval changes in Biological products: Quality, Safety and Efficacy Documents

- Preparation of Quality Information for Drug Submission for New Drug Approval: Biotechnological/Biological Products

- Guidelines and Handbook for Institutional Biosafety Committees (IBSCs), 2011

- Guidelines on Similar Biologics: Regulatory Requirements for marketing authorization in India 2012 


\section{Competent authorities}

The competent authorities involved in the approval process are as follows:

\section{Institutional Biosafety Committee (IBSC)}

IBSC is required to be constituted by any person including research institutions handling hazardous microorganisms and/or genetically engineered organisms. IBSC is responsible for ensuring biosafety on-site, along with initial review of applications to be recommended to RCGM. IBSC is also assigned with the responsibility to review and authorize firm for exchange of aforesaid organisms for the purpose of research.

\section{Review Committee on Genetic Manipulation (RCGM)}

RCGM is functioning from the Department of Biotechnology (DBT), Ministry of Science and Technology, Government of India. In the context of Similar Biologics, RCGM is responsible for authorizing the conduct of research and development, exchange of genetically engineered cell banks for the purpose of research and development and review of data up to preclinical evaluation (EMA guideline, 2014).

\section{Genetic Engineering Appraisal Committee (GEAC)}

GEAC functions under the Ministry of Environment and Forests (MoEF) as statutory body for review of applications and approval of activities where final drug product contains genetically modified organisms/living modified organisms (RCGM and GEAC are statutory committees set up as per provisions of Rules, 1989) (EMA guideline, Oct 2014).

\section{Central Drugs Standard Control Organization (CDSCO)}

CDSCO, headed by the Drug Controller General of India (DCGI) is apex regulatory body under Ministry of Health \& Family Welfare (MoHFW), Government of India, which is responsible for the approval of clinical trials as well as new drugs. In the context of Similar Biologics, CDSCO is responsible for clinical trial approval (also grants permission for import of drugs for clinical trial and export of clinical samples for biochemical and immunological analysis) and permission for manufacturing and marketing (CDSCO functions as per the provisions of the Drugs and Cosmetics Act 1940) (EMA guideline, Dec 2014).

\section{Principles for development of Similar Biologics}

Similar Biologics are developed through a sequential process to demonstrate the Similarity by extensive characterization studies revealing the molecular and quality attributes with regard to the Reference Biologic.

Reference Biologic is an innovator's product approved after evaluation of complete dossier is critical for the development of Similar Biologic.

The Reference Biologic has to be used in all the comparability exercises with respect to quality, preclinical and clinical considerations. The following factors should be considered for selection of the Reference Biologic:

- The Reference Biologic should be licensed/approved in India or ICH countries and should be the innovator's product. The Reference Biologic should be licensed based on a full safety, efficacy and quality data. Therefore another Similar Biologic cannot be considered as a choice for Reference Biologic.

- In case the Reference Biologic is not marketed in India; the Reference Biologic should have been licensed in any ICH countries. The Reference Biologic product can be imported for developing the Similar Biologic for quality, pre-clinical and clinical comparability.

- The same Reference Biologic should be used throughout the studies supporting the safety, efficacy and quality of the product (i.e. in the development Programme for the Similar Biologic).

- The dosage form, strength and route of administration of the Similar Biologic should be the same as that of the Reference Biologic.

- The active drug substance (active ingredient) of the reference biologic and that of Similar Biologic must show to be similar.

The acceptance of an innovator product as a Reference Biologic for evaluation of Similar Biologic does not imply approval for its use in India.

\section{Manufacturing process}

The Similar Biologics manufacturer should develop the manufacturing process to yield a comparable quality product in terms of identity, purity and potency to the Reference Biologic. and immunogenicity. . For the establishment and characterization of the cell banks, the guidelines issued by the ICH viz. Q5A, Q5B and Q5D should be referred for guidance (EMA guideline, Feb 
2006; EMA guideline, Dec 2007; ICH guideline, June 2011).

The data requirements for review of manufacturing process at preclinical submission stage include a complete description of the manufacturing process from development and characterization of cell banks, stability of clone, cell culture/fermentation, harvest, excipients, formulation, purification, primary packaging interactions (if different from Reference Biologic), etc. and the consequences on product characteristics.

\section{Molecular biology considerations}

The details regarding host cell cultures (including viral clearance), vectors, gene sequences, promoters etc. used in the production of Similar Biologic should be provided with appropriate drawings/figures. The detail of post-translational modifications (glycosylation, oxidation, deamination, phosphorylation etc.), if any should be explained.

\section{Upstream process development}

- Upstream process should be described in detail including media components used for cell growth

- At least three batches of reproducible fermentation data at pilot scale (batch size adequate to give enough purified products to generate preclinical data)

- Upstream process should be well controlled and monitored

- Details of upstream process kinetics data from consistency batches indicating cell growth, product formation, $\mathrm{pH}$, temperature, dissolved oxygen, major nutrient consumption pattern and agitation rate

- Concentration to be defined in terms of product/litre, yield and volumetric productivity

- Data to verify that the specific protein yield (amount of protein per unit cell mass) remains constant for all upstream batches

- Demonstrate that the overall productivity is reproducible and scalable

\section{Downstream process development}

Detail description of the methods followed for the cell harvesting and extraction of the protein.

- Steps involved in purification of protein

- Batch size for protein purification

- Description of each unit operation step during purification and recovery of protein along with quantitative recovery of product at each stage

- Describe the quality of the refolded protein if the starting material aggregated or from inclusion bodies and include details of the refolding process, specific activity at different doses, dose response curve, stability data and confirmation of solubility and absence of aggregation

- Consistency of recovery in three consecutive batches of purification from three independent batches of cell culture/ fermentation

- Describe post translational variation, if any

- Details of removal of impurities like product related variants \& impurities, and host cell \& process related impurities considered to pose a risk of Immunogenicity (EMEA 1997)

- Virus clearance validation studies

For clinical trial application, additional requirements are applicable as per CDSCO guidelines. Data for submission should include:

- Detailed description of the drug substance and drug product processes

- Crucial and key Quality Attributes of the product

- Manufacturing process controls

- Crucial process parameters

- Stability data

- Comparability of product manufactured at clinical scale against Reference Biologic

- Data from consistency batches and/or process validation batches as applicable

\section{Quality based considerations for Similar Biologics \\ Analytical methods}

The analytical methods should be chosen for establishing product comparability as per the crucial quality attributes of the product. For certain attributes (e.g. product aggregation) it is customary to use multiple, orthogonal methods for characterization. Extensive state of the art analytical methods should be applied to detect even slight differences" in all relevant quality attributes. Indian Pharmacopoeia monograph should be followed, if available. . The methods used to measure quality attributes for batch release, stability studies and in-process controls should be validated in accordance with ICH guidelines (ICHQ2, Q5C, Q6B), as appropriate (KFDA, 2010; WHO guideline, 2009; 2013). The characterization studies should include samples of the applicant's r-DNA derived product, 
Reference Biologic as control, known positive standard and negative control, wherever relevant. To ensure the statistical analysis, each quantitative experiment should be done at least three times and data should be represented in terms of mean and standard deviation. Appropriate statistical significance should be represented throughout the characterization data. Physicochemical and Biological characterization methods to be used for r-DNA derived products are given in Annexure II. It may be noted that this Annexure II is suggestive but not limited to the specified method and the requirements may vary on case by case.

\section{Product characterization}

Characterization studies for Similar Biologics include physicochemical properties, Biological activity, immunological properties, functional assays, purity (process and product-related impurities etc.), contamination, strength and content. Principles outlined in the ICH Q6B guideline should be followed. Indian Pharmacopoeia monograph should be followed, if available.

\section{Structural and physicochemical properties}

The analysis of physicochemical characteristic should include determination of primary and higher order structure of the drugs substance and the product along with other significant physicochemical properties. The target amino acid sequence of the Similar Biologic should be confirmed and is expected to be the same as for the Reference Biologic. Analytical methods that are used (including Biological and functional assays) should have acceptable precision and accuracy. In cases, where post translational modifications are taking place, these modifications need to be identified and quantified. In case any significant differences are found, these should be scientifically justified and critically examined in preclinical studies and clinical trials.

\section{Biological activity}

Biological products may have multiple biological activities. In such cases, appropriate biological assays will be required to characterize the activity and establish the products mechanisms of action and clinical effects (in units of activity). The data from biological assays will supplement the physicochemical characterization of the product as described in the section 6.3.1. Biological assays should be validated against an international or national Reference standard, where available and appropriate. If no such standards are available, an internal Reference standard must be established as per the ICH guidelines. If the methods of bioassay(s) are documented in the specification, test(s) can be conducted accordingly.

\section{Immunological properties}

The manufacturing process of Similar Biologics is known to affect the level of process related impurities and post translational modifications of the product. These characteristics may affect the immunogenicity of the product. Hence evaluation by characterization (antibody or antibody-derived product); comparison to Reference Biologic with respect to specificity, affinity, binding strength and Fc function; and evaluation by animal studies should be performed.

\section{Purity and impurities}

Characterization of a Similar Biologic requires evaluation of the following via a combination of analytical procedures:

- Product related variants (e.g. glycoforms, isomers etc.)

- Product related impurities (e.g. Aggregated, oxidized or deamidated product)

- Host cell related impurities (e.g. host cell protein, host cell DNA etc.)

- Process related impurities (residual media components, resin leachates etc.)

\section{Specifications}

Specifications of Similar Biologics (for drug substance and drug product) are established around quality attributes (QAs) with the intent of ensuring consistency in product quality and comparability to Reference Biologic according to relevant guideline (ICH Q6B). Methods used for setting specifications may or may not be the same as the analytical methods used for product characterization and for establishing product comparability. Acceptance limits should be set based on Reference Biologic data and data from sufficient number of batches from pre clinical or clinical batches, which must be in line with international norms.

\section{Stability}

The shelf-life and storage condition of drug substance and drug product should be assigned based on real-me stability studies. Stability studies on drug substance and drug product 
should be carried out using containers and conditions that are representative of the actual storage containers and conditions, according to relevant guidelines (e.g. ICHQ1A(R2), ICHQ5C, WHOTRS822) (EMA guideline, Jun 1997). Sideby-side accelerated and stressed stability studies comparing the Similar Biologic to the Reference Biologic will be of value in determining the Similarity of the products by showing comparable degradation profiles (ICH guideline, Feb 2003).

\section{Quality comparability study}

he quality comparison between Similar Biologic and Reference Biologic essential. The applicant should submit a full quality dossier as per CDSCO guidance or industry, 2008 including the results of comparability exercise for the Similar Biologic with the Reference Biologic before the applicant proposes to take the Similar Biologic to clinical development.

First three consecutive standardized batches which have been used to demonstrate consistency of the manufacturing process should be used. The quality comparison between the Similar Biologic and the reference Biologic should be governed by Quality Attributes (QAs), which employ state-of-the-at high resolution analytical techniques and methods that are sensitive enough to detect the possibilities of changes to the product.

From the perspective of establishing similarity, Quality Attributes of a Similar Biologic may be considered in two categories; Critical Quality Attributes (CQA) and Key Quality Attributes (KQA):

\section{Critical quality attributes}

CQA are those Quality Attributes which have direct impact on the clinical safety or efficacy. All attributes that directly impact the known mechanism(s) of action of the molecule fall in this category. CQAs must be controlled within limits that need to be established based on the Reference Biologic.

\section{Key quality attributes}

KQA are those Quality Attributes which are not known to impact clinical safety and efficacy but are considered relevant from a product and process consistency perspective. Attributes that do not impact the known mechanism(s) of action of the molecule fall in this category. KQAs must necessarily be controlled within acceptable limits; however it may acceptable to have slight differences in comparison to the Reference Biologic.

\section{Data requirements for preclinical studies Prerequisite for conducting preclinical studies} The applicant has to comply with the RCGM requirements like demonstration of consistency of the process and product, product characterization and product specifications. The applicant should submit the data generated along with the following basic clinical information and preclinical study protocols to RCGM for obtaining permission. The toxicology studies should be initiated as per the approval of RCGM. The basic information about the Reference Biologic and Similar Biologic (Genazzani et al 2007) may include the following:

\section{Basic information about the Reference Biologic}

- Information about the drug, route of administration, absorption and elimination rate, therapeutic index, dose, vehicle, mode of administration, dose response etc.

- Bioequivalence range, if available

- Tissue-specific localization, if available

- Available toxicity data on Reference Biologic

- Mode of action

\section{Basic information about the Similar Biologic}

- Known /proposed clinical use

- Target population (Age, sex, pregnancy, lactating, children etc.)

- Dosage (frequency and intervals) units

- Route / alternate routes of administration

- Final formulation + adjuvants, additives etc.

- Toxicology data of adjuvants

- Diluents

- Presentation e.g. pre-filled syringe, cartridge, vial

\section{Preclinical studies \\ Pharmacodynamics studies}

In vitro studies

Comparability of Similar Biologic and Reference Biologic should be established by in vitro cell based bioassay (e.g. Cell proliferation assays /cytotoxicity / neutralizing / receptor binding assays)

\section{In vivo studies}

In vivo evaluation of Biological/pharmacodynamics activity may be dispensable if in vitro 
assays are available, which are known to reliably reflect the clinically relevant pharmacodynamics activity of the Reference Biologic. In cases where the in vitro assays do not reflect the pharmacodynamics, In vivo studies should be performed as applicable (Schellekens, 2009).

\section{Toxicological studies}

In case of in vivo toxicity studies, at least one repeat dose toxicity study in a pharmacologically relevant species is required to be conducted with an intended route of administration. Depending on the route of administration, local tolerance should be evaluated. This evaluation, if feasible may be performed as a part of above mentioned repeated-dose toxicity study. Accordingly, the study groups of animals in repeated-dose toxicity testing will consist of:

- Historical Control (Optional)

- Vehicle Control

- Vehicle Control for recovery group

- Formulation without protein (for vaccines) if multiple adjuvants - each to be checked independently

- 1X Similar Biologic for study duration (lowest dose)

- 1X Reference Biologic for study duration

- 2X Medium dose Similar Biologic

- 5X High dose Similar Biologic

- Similar Biologic with a recovery group going beyond the end of study period for 7 to 14 days

The protocols and the study reports should provide complete details of various steps in the toxicity testing as indicated below:

- Procedures prior to euthanasia e.g. blood drawing, body weight, etc

- Events immediately as per euthanasia, necropsy, gross description, organ weights and organs sampled for histopathology

- Biochemical parameters- Equipment and methods used units of measurement and expression

- Haematology procedures and parametersmethod to be used (automated or manual)

- Statics methods used

- Bone marrow either examined as an aspirate/smear or on histopathology section

In case of histopathological observations, the applicants should consider the following points:
- Every observation considered as deviation from described normal histology needs to be documented and the incidence of each of these in the different groups should be denoted.

Whether such a feature is significant or not can be decided on review of statistical significance or dose response or if it is within or outside the normal range of values in case of biochemical and haematological observations.

- If all organs from all animals were not examined e.g. in 5 animals only 4 livers were examined, the reason for the 1 liver not being examined should be documented.

- In case of premature death or morbidity the proposed course of action is to be included in the protocol.

Other toxicity studies, including safety pharmacology, reproductive toxicity, mutagenicity and carcinogenicity studies are not generally required for evaluation of a Similar Biologic unless warranted by the results from the repeated-dose toxicological studies.

The final report of the study should reflect all the aspects approved in the protocol and the following additional sections/documents:

- RCGM approval of protocol and test centre

- IBSC approval of report

- IAEC approval for animal use and for the procedures

- QA statement

- Signatures of study director and all investigators who were involved in the study

- All quality analytical reports on the test material and vehicle

- Animal feed and animal health certifications. Protocol deviations if any

- Discussion on the results

- Individual animal data, summary data and any other data like computer analysis outputs etc

- Conclusion

\section{Immune responses in animals}

Antibody response to the Similar Biologic should be compared to that generated by the reference Biologic in suitable animal model. The test serum samples should be tested for reaction to host cell proteins. The other parameters for evaluating immune toxicity include immune 
complexes in targeted issues may be considered while evaluating histopathology observations, etc. As per complexion of preclinical studies the reports are submitted to RCGM for review and consideration. Other toxicity studies, including safety pharmacology, reproductive toxicity, mutagenicity and carcinogenicity studies are not generally required for valuation of a Similar Biologic unless warranted by the results from the repeated-dose toxicological studies (EMA guideline, Mar 2010).

\section{Data requirements for clinical trial application \\ Pharmacokinetic (PK) studies}

The PK data should support the subsequent Phase III clinical development given that the purported Similar Biologic would be established to be similar as the Reference Biologic product. As per complexion of extensive characterization comparability on quality attributes, a PK study of the Similar Biologic in comparison with the Reference Biologic product may be performed in an appropriate number of:

- Normal Healthy Volunteers (NHV) and or

- Patents

The design of comparative pharmacokinetic studies should take the following factors into consideration:

- Half life

- Linearity of PK parameters

- Endogenous levels and diurnal variations of Similar Biologic under study (where applicable)

- Conditions and diseases to be treated

- Route(s) of administration, and

- Indications

Appropriate design considerations include:

- Single dose, comparative, PK studies

- Parallel arm or

- Cross over

- Multiple dose, comparative parallel arm steady state PK studies

In sequential development approach, the Normal Healthy Volunteers (NHV) study is performed before the Phase III safety and efficacy study.

\section{Single dose comparative PK studies}

Dosage in the PK study should be within the therapeutic dose range of reference Biologic. Appropriate rationale for dose selection should be provided. The route of administration should be the one where the sensitivity to detect differences is the largest. Sample size should have statistical rationale (i.e. statistically justified) and comparability limits should be defined.Differences in elimination kinetics between Similar Biologic and reference Biologic e.g. clearance and elimination half-life should be explored. Similarity in terms of absorption/bioavailability should not be the only parameters of interest.A parallel arm design study is more appropriate for Similar Biologics with along half-life or for proteins for which formation of antibodies is likely or if study is being done in patents. In case of short half-life, cross over design may be considered with a scientific justification.

\section{Multiple dose comparative PK studies}

Multiple-dose, comparative, parallel arm steady state PK studies are required for a Similar Biologic that is used in a multiple dose regimen, where markedly higher or lower concentrations are expected at steady state than that expected from single dose data PK measurements, and where me-dependence and dose-dependence of PK parameters cannot be ruled out. In case multi-dose comparative PK studies are not done adequate justification should be provided.

\section{Pharmacodynamics studies}

As required for the PK studies in the Similar Biologic clinical development program, the pharmacodynamics (PD) studies should also be comparative in nature. Comparative, parallel arm or cross-over, PD study in most relevant population (patients or healthy volunteers) is required for detecting differences between Similar Biologic and Reference Biologic. If a PD marker is available in healthy volunteers, PD in healthy volunteers can be done, unless considered unethical due to expected adverse events and toxicity e.g. oncology drugs.Comparative PD studies are recommended when the PD properties of the Reference Biologic are well characterized with at least one PD marker validated for a clinical outcome of the molecule. The relationship between dose/exposure, the relevant PD marker(s) and response efficacy of the Reference Biologic should be well established and used to justify the design. The acceptance ranges for the demonstration no of Similarity in PD parameters should be predefined and appropriately justified. The parameters investigated in PD studies 
should be clinically relevant and surrogate markers should be clinically validated. PD studies may be combined with PK studies, in which case the PK/PD relationship should be characterized. If PD marker is not available and the PK can be done in Patients then the PK study can be combined with phase III clinical study. The PD study can also be a part of Phase III clinical trials wherever applicable (Minghetti et al 2011).

\section{Confirmatory safety and efficacy study}

The establishment of in-vitro, pre-clinical and PK/PD Similarity as described in earlier section is important as robust, high quality processes, a comprehensive equality comparison and comparative preclinical and PK/PD studies help in demonstrating the Similarity of the Similar Biologics in these settings. Information to establish comparative safety and efficacy in relevant patient population is mandatory for all Similar Biologics. Comparative clinical trials are critical to demonstrate the similarity in safety and efficacy profiles between the Similar Biologic and Reference Biologic with few exceptions (e.g. recombinant human soluble insulin products for which only comparative clinical safety study is required). The study should be conducted in a sensitive and homogenous patient population with appropriate sensitive primary end points as per requirement of a Phase III clinical trial. . Equivalence, non-inferiority or comparability Phase III clinical trials may be conducted based on comparability established during physicochemical characterization, preclinical and PK/PD studies, as per approval of design and protocol by CDSCO. However, the comparability Phase III clinical trials intended for seeking marketing approval of Similar Biologics falling under the category of new drugs as per Drugs and Cosmetics Rules, 1945 shall be conducted in accordance with the Indian Good Clinical Practice (GCP) guidelines, generally in not less than hundred evaluable patients in test arm to evaluate the safety, efficacy and comparability (Malik, 2009).

\section{Waiver of safety and efficacy study}

The confirmatory clinical safety and efficacy study can be waived if all the below mentioned conditions are met:

- Structural and functional comparability of Similar Biologic and Reference Biologic can be characterized to a high degree of confidence by physicochemical and in vitro techniques

- The Similar Biologic is comparable to Reference Biologic in all preclinical evaluations conducted

- PK/PD study has demonstrated comparability of PD markers validated for clinical outcome and has preferentially been done in an inpatient setting with safety measurement (including meaningful immunogenicity assessment) for adequate period justified by the applicant and efficacy/PD measurements

- A comprehensive post-marketing risk management plan has been presented that will gather additional safety data with a specific emphasis on gathering immunogenicity data.

The confirmatory clinical safety and efficacy study cannot be waived especially for large molecular weight biologics like Monoclonal antibodies. Wherever the phase III trial is waived, the immunogenicity should have been gathered in the PK/PD study and will also need to be generated during post- approval Phase IV study. The confirmatory clinical safety and efficacy study cannot be waived if there is no reliable PD marker validated for clinical outcome.

\section{Non-comparative safety and efficacy study}

For a product which is found Similar in preclinical, in-vitro characterization having established PK methods and a PD marker that is surrogate of efficacy, the residual risk is significantly reduced in the Phase I study if equivalence is demonstrated for both PK and PD. Phase III clinical trials of such a Similar Biologics product may be waived as noted above or, where considered necessary, an appropriate single arm study in at least 100 evaluable subjects may be carried out in the most sensitive indication to address any residual uncertainty.

\section{Safety and immunogenicity data}

Both pre-approval and post-approval assessment of safety is desired to be conducted for a Similar Biologic. Regarding pre-approval safety assessment, comparative pre-approval safety data including the immunogenicity data is required for all Similar Biologics including those for which confirmatory clinical trials have been waived. This pre-approval safety data is primarily intended to provide assurance of the 
absence of any unexpected safety concerns. . Similar Biologic drug, the number of patients in phase IV study can be modified accordingly so that the safety data (from both Phase III and IV) is derived from a minimum of 300 patients treated with the Similar Biologics.

\section{Extrapolation of efficacy and safety data to other indications}

Extrapolation of the safety and efficacy data of a particular clinical indication (for which clinical studies has been done) of a Similar Biologic to other clinical indications may be possible if following conditions are met:

- Similarity with respect to quality has been proven to Reference Biologic

- Similarity with respect to preclinical assessment has been proven to Reference Biologic

- Clinical safety and efficacy is proven in one indication

- Mechanism of action is same for other clinical indications

- Involved receptor(s) are same for other clinical indications

- However, new indications not mentioned by innovator will needs to be covered by a separate application

\section{Data requirements for market authorization application}

The applicant should submit application for market authorization as per CDSCO guidance document for industry, 2008. For cases where commercial manufacturing is performed either at a different scale and/or with a different process as compared to that used for manufacturing phase III clinical trial batches, then information on comparability of quality needs to be additionally submitted with appropriate justification and will be dealt with on a case to case basis.

\section{Post-market data for Similar Biologics Pharmacovigilance plan}

The clinical studies done on Similar Biologics prior to market authorization are limited in nature so the rare adverse events are unlikely to be encountered. Hence comprehensive pharmacovigilance plan should be prepared by manufacturer to further revaluate the clinical safety in all the approved indications in the post marketing phase. The pharmacovigilance plan should include the submission of periodic safety update reports (PSURs). The PSURs shall be submitted every six months for the first two years as per approval of the Similar Biologic is granted to the applicant. For subsequent two years the PSURs need to be submitted annually to DCGI office as per the Schedule.

\section{Post marketing studies (Phase IV study)}

The primary aim of the post marketing phase IV study is safety and hence following parameters should be considered for the post marketing phase IV study protocol:

- Primary endpoint: Safety

- Secondary endpoint: Efficacy and Immunogenicity

The phase IV protocol should be submitted along with marketing authorization application for approval. The clinical studies done on Similar Biologics prior to market authorization are limited in nature so post marketing studies should be conducted and the reports be submitted to DCGI. The plan of post market studies should be captured in Pharmacovigilance plan and update on the studies should be submitted to the CDSCO.

Rationale on the strategy for testing immunogenicity should be provided. Assay methods should be validated and should be able to characterize antibody content as well as the type of antibodies formed. In the case of Similar Biologics that can be evaluated for rare diseases, the clinical trial population size can be reduced as per the rarity and severity of the disease as well as the limitation of access to therapeutic options.

\section{Approval process \\ Requirements for approval of Biosimilars Products}

Principles of Biosimilars approach

A biotechnological product that is proved to be comparable to an already approved reference product in quality, non-clinical and clinical evaluation.

\section{Regulatory perspectives for Biosimilars Products}

- Existing generic definition is not appropriate for biosimilars

- Approval of the biosimilars product should be based on the demonstration of similarity to a suitable reference drug with comprehensive comparative data (Table 2) 
- Comprehensive characterization and comparison at quality level shall provide basis for reduction in non-clinical/clinical data
- A final determination of similarity can be based on a combination of quality, nonclinical and clinical evaluation

Table 2. Dossier requirements for approval process

\begin{tabular}{|c|c|c|c|}
\hline Part & Evaluation & New Biologics & Biosimilars \\
\hline Module 1 & - & Full & Full \\
\hline Module 2 & - & Full & Full \\
\hline Module 3 & Quality & Full & Full + Comparability \\
\hline Module 4 & Non-clinical & Full & Reduced + Comparability \\
\hline Module 5 & Clinical & Full & Reduced + Comparability \\
\hline
\end{tabular}

\section{Reference drug}

- The reference drug should be already approved on the basis of a complete dossier package in Korea

- The reference drug should be used throughout the studies supporting the quality, safety, and efficacy of the product

- The dosage form, strength, and route of administration of the biosimilars product should be the same as that of the reference product

- The biosimilars product should not be used as a reference drug

\section{Requirements for quality studies}

Full CMC and comparability exercise data between biosimilars product and reference product are required:

- Extensive side by side characterization

- Physicochemical properties (including Immunochemical properties)

- Biological activity

- Specification

- Impurities

- Stability

\section{Demonstration of similarity}

The demonstration of comparability does not necessarily mean that the quality attributes of the two products will be identical, but they are highly similar with two consequences.

- Minor structural differences such as variability in post- translational modifications may be acceptable but, must be justified

- Differences in impurity profiles should be justified

- The impact of observed differences in the quality attributes should be assessed and then non-clinical and clinical studies should be designed and conducted on the basis of the results

\section{Requirements for non-clinical studies}

Comparative non-clinical studies should be designed to detect significant differences between the biosimilars product and the reference product:

\section{- In vitro study}

Receptor binding study

Cell proliferation assay

\section{- In vivo study}

Biological / pharmacodynamics studies relevant to the clinical application

\section{- Toxicity}

At least one repeat dose toxicity study in a relevant species, including toxic kinetic study, antibody measurement.

\section{Requirements for clinical studies}

Comparative clinical trials are required depending on the data in terms of quality and nonclinical studies.

- Pharmacokinetic studies/pharmacodynamics studies

- Clinical Efficacy and safety trials

- Confirmatory PK/PD studies

\section{Issues on clinical evaluation}

- Treatment practices with reference product may have changed and effect on clinical study design and recruitment

- Choice of appropriate clinically relevant endpoints is important

- Cross-over studies may not be appropriate for protein therapeutics with a long half-life

- Patient population may affect sensitivity ; adequate population to detect a clinically meaningful difference

- Setting a relevant similarity margin; equivalence trials may need to be very large 
- There is a need to build capacity for expertise; clinical and statistical consideration

\section{Reference drug}

- Need to prevent duplication of clinical studies in each region

\section{Extrapolation of indication}

- Need to have more a comprehensive and accurate approach to specify which data are based on extrapolation

\section{Interchangeability}

- Currently, no clinical studies have been undertaken to asses clinical outcomes or repeated switches of a biologic product

\section{Post-marketing pharmacovigilance}

- Pre-approval clinical safety data are insufficient to identify all the potential safety profiles; immunogenicity (Biospectrumasia regulatory, 2012)

\section{Available Biosimilar Drugs in India}

There have been established guidelines for approving Generic version of small molecule chemical drugs in India for some time already. However, no specific guidelines for "Similar Biologics", as the Indian regulatory authorities call these products, have existed in India until recently. This has been the case despite the fact that the requirements for granting regulatory approval for "Similar biologics" required more data than for a simple generic drug application. India announced the release of draft regulatory guidelines for "Similar Biologics" at the BIO industry conference in Boston, USA, on $19^{\text {th }}$ June 2012. Finalised guidelines were implemented on $15^{\text {th }}$ September 2012. The guidelines outline a simple abridged procedure for evaluation of "Similar biologics" which have been approved and marketed in India, Europe or USA for more than 4 years. The regulatory bodies responsible for approval of "Similar biologics" in India are the Department of Biotechnology (DBT-Under the ministry of Science and Technology), through its Review Committtee on Genetic Manipulation (RCGM), and the Central Drugs of Standard Control Organization (CDSCO under the Ministry of Health and Family Welfare, CDSCO guideline, 2012) (Table 3).

Table 3. "Similar biologics" approved and marketed in India

\begin{tabular}{|c|c|c|c|c|}
\hline $\begin{array}{l}\text { Product } \\
\text { Name* }\end{array}$ & Active Substance & Therapeutic area & $\begin{array}{l}\text { Approval/Launc } \\
\text { h date in India }\end{array}$ & Company \\
\hline Abcixi Rel & abciximab & Angina, Cardiac ischemia & 23 Apr 2013 & $\begin{array}{c}\text { Reliance } \\
\text { Life sciences }\end{array}$ \\
\hline Actorise & darbepoetin alfa & $\begin{array}{l}\text { Anaemia, Cancer, Chronic } \\
\text { kidney failure. }\end{array}$ & 6 Jan 2014 & Cipla/Hetero \\
\hline Adfrar & adalimumab & $\begin{array}{l}\text { Ankylosing spondylitis, } \\
\text { Plaque Psoriasis, Psoriatic } \\
\text { arthiritis, Rheumatoid } \\
\text { arthritis, Ulcerative colitis }\end{array}$ & 11 Jan 2016 & $\begin{array}{c}\text { Torrent } \\
\text { Pharmaceuticals }\end{array}$ \\
\hline Basalog & insulin glargine & Diabetes & 2009 & Biocon \\
\hline Bevacirel & bevacizumab & Colorectal cancer & 10 Jun 2016 & $\begin{array}{c}\text { Reliance Life } \\
\text { Sciences (Lupin) }\end{array}$ \\
\hline Biovac-B & hepatitis B vaccine & Hepatitis B & 2000 & Wockhardt \\
\hline CanMab & trastuzumab & Breast cancer & 23 Oct 2013 & Biocon \\
\hline Ceriton & epoetinalfa & $\begin{array}{l}\text { Anaemia, Cancer, Chronic } \\
\text { kidney failure }\end{array}$ & NR & Ranbaxy \\
\hline Choriorel & $\begin{array}{c}\text { chorionic } \\
\text { gonadotrophin } \\
\text { hormone r-hCG }\end{array}$ & Female in fertility & 22 Jun 2011 & $\begin{array}{l}\text { Reliance Life } \\
\text { Sciences }\end{array}$ \\
\hline Cizumab & bevacizumab & Colorectal cancer & 27 Jun 2016 & Hetero \\
\hline Cresp & darbepoetin alfa & $\begin{array}{c}\text { Anemia, Cancer, Chronic } \\
\text { kidney failure }\end{array}$ & 23 Mar 2010 & $\begin{array}{c}\text { Reddy's } \\
\text { Laboratories }\end{array}$ \\
\hline Darbatitor & darbepoetin alfa & $\begin{array}{l}\text { Anemia,Cancer Chronic } \\
\text { kidney failure. }\end{array}$ & 2014 & $\begin{array}{c}\text { Torrent } \\
\text { Pharmaceuticals }\end{array}$ \\
\hline Emgrast & filgrastim & Cancer, neutropenia & 16 Mar 2010 & $\begin{array}{c}\text { Gennova Bio } \\
\text { Pharmaceutical } \\
\text { (Emcure) }\end{array}$ \\
\hline
\end{tabular}




\begin{tabular}{|c|c|c|c|c|}
\hline Epofer & epoetinalfa & $\begin{array}{c}\text { Anemia, Cancer, Chronic } \\
\text { kidney failure }\end{array}$ & NR & Emcure \\
\hline Epofit/Erykine & epoetinalfa & $\begin{array}{l}\text { Anemia, Cancer. Chronic } \\
\text { kidney failure }\end{array}$ & Aug 2005 & $\begin{array}{c}\text { Intas } \\
\text { Pharmaceuticals }\end{array}$ \\
\hline Eporec & erythropoietin & $\begin{array}{l}\text { Anaemia, Chronic kidney } \\
\text { failure. }\end{array}$ & 9 Aug 2011 & Bioviz Technologies \\
\hline Epotin & epoetinalfa & $\begin{array}{l}\text { Anemia, Cancer. Chronic } \\
\text { kidney failure }\end{array}$ & NR & Claris Life Sciences \\
\hline Erypro & epoetinalfa & $\begin{array}{l}\text { Anemia, Cancer Chronic } \\
\text { kidney failure }\end{array}$ & NR & Biocon \\
\hline Etacept & etanercept & $\begin{array}{c}\text { Ankylosing spondylitis, } \\
\text { Psoriatic arthiritis, } \\
\text { Rheumatoid arthritis }\end{array}$ & Apr 2013 & Cipla \\
\hline Exemptia & adalimumab & Rheumatoid arthritis & 25 Sep 2014 & ZydusCadila \\
\hline Ferast & filgrastim & Cancer, neutropenia & NR & Claris Life Sciences \\
\hline Filgrastim & filgrastim & Neutropenia & 22 Oct 2013 & $\begin{array}{c}\text { Cadila } \\
\text { Pharmaceuticals }\end{array}$ \\
\hline Filgrastim & filgrastim & Neutropenia & 5 Mar 2013 & Lupin \\
\hline Filgrastim & filgrastim & Neutropenia & 3 Jun 2013 & USV \\
\hline Folisurge & $\begin{array}{l}\text { folitropinalfa (follicle } \\
\text { stimulating hormone) }\end{array}$ & $\begin{array}{l}\text { Female infertility, } \\
\text { spermatogenesis } \\
\text { (in man) }\end{array}$ & 14 May 2013 & $\begin{array}{c}\text { Intas } \\
\text { Pharmaceuticals }\end{array}$ \\
\hline Fostirel & $\begin{array}{l}\text { folitropinalfa (follicle } \\
\text { stimulating hormone }\end{array}$ & Female infertility & 30 Apr 2010 & $\begin{array}{c}\text { RelianceLife } \\
\text { Sciences }\end{array}$ \\
\hline Glaritus & insulin glargine & Diabetes mellitus & Mar 2009 & Wockhardt \\
\hline Insugen & human insulin & Diabetes mellitus & NR & Biocon \\
\hline Insulin & insulin & Diabetes mellitus & 9 Aug 2011 & Gland pharma \\
\hline Maball & rituximab & $\begin{array}{l}\text { Lymphoma, on-Hodgkin's } \\
\text { Lymphoma }\end{array}$ & 3 Feb 2015 & Hetero group \\
\hline MabTas & rituximab & $\begin{array}{l}\text { Lymphoma, on-Hodgkin's } \\
\text { Lymphoma }\end{array}$ & 26 Feb 2013 & $\begin{array}{c}\text { Intas } \\
\text { Pharmaceuticals }\end{array}$ \\
\hline Neupeg & pegfilgrastim & Cancer, Neutropenia & Aug 2007 & $\begin{array}{c}\text { Intas } \\
\text { Pharmaceuticals }\end{array}$ \\
\hline Nufil & filgrastim & Cancer, Neutropenia & NR & Biocon \\
\hline Peg-filgrastim & pegfilgrastim & Cancer, Neutropenia & 3 Sept 2013 & Lupin \\
\hline Peg-grafeel & pegfilgrastim & Cancer,Neutropenia & 10 May 2011 & $\begin{array}{c}\text { Dr Reddy's } \\
\text { Laboratories }\end{array}$ \\
\hline Rasburicase & rasburicase & $\begin{array}{c}\text { Malignancy assosciated } \\
\text { hyperuricemia }\end{array}$ & 28 Aug 2012 & Virchow Biotech \\
\hline Relibeta & interferon beta-1a & Multiple sclerosis & 2 May 2011 & $\begin{array}{c}\text { Reliance Life } \\
\text { Sciences }\end{array}$ \\
\hline Religrast & filgrastim & Neutropenia & 2008 & $\begin{array}{l}\text { Reliance Life } \\
\text { Sciences }\end{array}$ \\
\hline Shankinase & streptokinase & $\begin{array}{c}\text { Arterial occlusions, Deep } \\
\text { vein thrombosis, } \\
\text { Pulmonary embolism } \\
\end{array}$ & Jun 2004 & $\begin{array}{c}\text { Shantha } \\
\text { Biotechnis/ } \\
\text { Merieux Alliance } \\
\end{array}$ \\
\hline Shanpoietin & erythropoietin & $\begin{array}{l}\text { Anaemia, Chronic kidney } \\
\text { failure }\end{array}$ & Jan 2005 & $\begin{array}{c}\text { Shantha } \\
\text { Biotechnis/ } \\
\text { Merieux Alliance }\end{array}$ \\
\hline Terifrac & $\begin{array}{l}\text { teriparatide } \\
\text { (parathyroid } \\
\text { hormone) }\end{array}$ & $\begin{array}{c}\text { Post-menopausal women } \\
\text { with osteoporosis who are } \\
\text { at high risk for fracture }\end{array}$ & 1 Nov 2010 & $\begin{array}{c}\text { Intas } \\
\text { Pharmaceuticals }\end{array}$ \\
\hline Teriparatide & $\begin{array}{l}\text { teriparatide } \\
\text { (parathyroid } \\
\text { hormone) }\end{array}$ & $\begin{array}{c}\text { Post-menopausal women } \\
\text { with osteoporosis who are } \\
\text { at high risk for fracture }\end{array}$ & 21 Aug 2012 & Cadila Healthcare \\
\hline Teriparatide & $\begin{array}{l}\text { Teriparatide } \\
\text { (parathyroid } \\
\text { hormone) }\end{array}$ & $\begin{array}{c}\text { Post-menopausal women } \\
\text { with osteoporosis who are } \\
\text { at high risk for fracture }\end{array}$ & 13 Aug 2012 & USV \\
\hline
\end{tabular}




\begin{tabular}{|c|c|c|c|c|}
\hline Wepox & epoetin alfa & $\begin{array}{c}\text { Anaemia, Cancer, Chronic } \\
\text { kidney failure }\end{array}$ & Mar 2011 & Wockhardt \\
\hline Wosulin & human insulin & Diabetes mellitus & 13 Aug 2003 & Wockhardt \\
\hline Zavinex & interferon alfa-2b & $\begin{array}{c}\text { Chronic hepatitis B } \\
\text { Chronic hepatitis C }\end{array}$ & 21 Jun 2011 & Cadila Healthcare \\
\hline Zyrop & erythropoietin & Chronic kidney failure & 28 Apr 2010 & Cadila Healthcare \\
\hline
\end{tabular}

\section{CONCLUSION}

Biosimilars are biological products that are the replicas of their innovator biopharmaceuticals. Specified regulations, and approval process of generic version of biologicals exists depending on the country. Each class of biologic varies in its benefit / risk profile, the nature and frequency of adverse events, the breadth of clinical indications, and whether surrogate markers for efficacy are available and validated. But most of the countries do not have specific guidelines for potential market biological products like monoclonal antibodies (mAbs), interferon beta, and insulin. The main points to consider about biosimilars are their safety, automatic

\section{REFERENCES}

CDSCO Guidelines on Similar Biologic: Regulatory Requirements for Marketing Authorization in India, New Delhi, Govt. of India, 2012.

EMA guideline, DNA and Host cell protein impurities, routine testing versus validation studies, London, June 1997. (CPMP/BWP/382/97)

EMA guideline on similar biological medicinal products containing biotechnology-derived proteins as active substance: non-clinical and clinical issues, London, February 2006. (EMEA/CHMP/BMWP/42832/2005)

EMA guideline on immunogenicity assessment of biotechnology-derived therapeutic proteins, London, December 2007. (EMEA/CHMP/BMWP/14327/2006)

EMA guideline on non-clinical and clinical development of similar biologic medicinal products containing recombinant erythropoietin (Revision), London, March 2010. (EMEA/CHMP/BMWP/301636/2008)

EMA guideline on similar biological medicinal products, London, October 2014. (CHMP/437/04 Rev 1)

EMA Guideline on Similar Biological medicinal products containing biotechnology- derived proteins as active substance: non-clinical and clinical issues, London, December 2014. (EMEA/CHMP/BMWP/42832/2005 Rev1)

Genazzani AA, Biggio G, Caputi AP, Del Tacca M, Drago F, Fantozzi R, Canonico PL. Biosimilar drugs: concerns and opportunities. BioDrugs 2007;21(6):351-6. [DOI: 10.2165 /00063030-200721060-00003] substitution, naming, and labelling/prescription. The safety profile of biosimilars is not identical to reference as seen for certain biosimilar products, and needs to show different precautions and warnings from reference. The immunogenicity of biosimilars cannot be fully predicted using preclinical/clinical studies. Robust pharmacovigilance still remains critical consideration. A manufacturer may well establish the design space for his product but cannot use this concept to ensure similarity with the reference. Every biological is different and healthcare professionals should interchange biologicals after careful analysis of supporting data.

Guideline for Safety Study of Biological Products (KFDA, 2010).

ICH guideline Q1A(R2) - Stability Testing of New Drug Substances and Products, February 2003.

ICH guideline (S6) R1 - Preclinical safety evaluation of biotechnology-derived pharmaceuticals, London, June 2011. (EMA/CHMP/ICH/731268/1998)

India defines pathway for biosimilars development, July 2012.

Malik NN. Controlling the cost of innovative cancer therapeutics. Nat. Rev. Clin. Oncol. 2009;6;550-2. [DOI: 10.1038/nrclinonc.2009.113]

Minghetti P, Rocco P, Del Vecchio L, Locatelli F. Biosimilars and regulatory authorities. Nephron Clin. Pract. 2011; 117(1):c1-7. [DOI: 10.1159/000319640]

Naik BV, Reddy ML, Haranadh CH, Sabareesh M, Umasankar K. A review on biosimilar drugs. Int. J. Res. Pharm. Nano Sci. 2014;3(2):153-8.

Schellekens H. Biosimilars therapeutics-what do we need to consider? NDT Plus 2009;2(S1):i27-36. [DOI: 10.1093/ndt plus/sfn177]

World Health Organization (WHO) guidelines on evaluation of similar biotherapeutic products (SBPs), October 2009.

World Health Organization (WHO) guidelines on the quality, safety and efficacy of biotherapeutic protein products prepared by recombinant DNA technology, Geneva, 2013.

https://www.novascientia.net 